\title{
Multi attribute decision making parametric optimization in weld bead by gas metal arc welding through grey relation analysis: A case study
}

\author{
Saadat Ali Rizvi ${ }^{1}$, Wajahat $\mathrm{Ali}^{2}$ \\ ${ }^{* 1}$ University Polytechnic, Jamia, Millia, Islamia,New Delhi, INDIA \\ ${ }^{2}$ Department of Mechanical Engineering, SCRIET (CCS University), Meerut, INDIA \\ Corresponding Author's e-mails: saritbhu@gmail.com/sarizvi1@jmi.ac.in \\ ORCID iD: https://orcid.org/0000-0002-3526-2428 (Rizvi), ORCID iD: https://orcid.org/https://orcid.org/0000-0003-0428-7064 (Ali)
}

\begin{abstract}
The basic purpose of this study was to identify the effect of gas metal arc (GMA) welding process parameters on the weld bead geometry of IS2062 structural steel of A grade. $\mathrm{L}_{16}$ Taguchi orthogonal array (OA) design with the idea of S/N (signal to noise) ratio was applied to obtain objective function to be optimized within the experimental field. In this research work the Taguchi technique was joined with grey relational analysis to solve the multi-response optimization problem. ANOVA (Analysis of Variance) was applied to estimate the most significant input parameters which contribute toward the output parameters. Arc voltage, gas flow rate, and wire feed speed were carefully selected as input parameters, whereas weld bead, depth of penetration, and reinforcement were output respectively. The optimal GMA welding process parameters were identified in order to enhance the productivity and curtail the overall functional cost of weld.
\end{abstract}

Keywords: grey-relational analysis (GRA), Taguchi technique, optimization, GMAW, ANOVA.

DOI: http://dx.doi.org/10.4314/ijest.v12i2.7

\section{Introduction}

In today's era GMA welding process is extensively used to weld a lot of variety materials. GMA welding is adopted due to the excellent quality of weld and the weld quality basically depends upon the mechanical properties of weldments. Weld bead geometry generally depends upon the different welding parameters. IS 2062 structural steel of grade A is a very common engineering material which is extensively used in various industries such as fabrication, building, pharmaceutical, chemical, nuclear and many more industries due to its excellent ductility, good heat resistance, and fair weldability (Rizvi and Ali, 2009). A very excellent good quality of weld can be fabricated by using the gas metal arc welding (GMAW) process. GMA welding is a semi-automatic process and appropriate to weld typically all types of engineering material (Sharma et al., 2014). Grey relational analysis coupled with the Taguchi method was applied to optimize the submerged arc welding process parameters for weld bead of mild steel plate (Datta et al., 2008) and it informed the user that grey based Taguchi technique is suitable to continuous improvement in product quality of component. Another researcher used the grey relational analysis (GRA) with Taguchi technique to determine the multi-response optimization of TIG welding process for most favorable parametric mixture to yield favorable weld bead geometry of weldments by clubbing (Esme et al., 2009). Weld bead geometry parameters were also optimized by grey relational analysis during the plasma arc welding of AISI 304L and it was observed that the optimal weld bead geometry was obtained at a 8A peak current,5A back current, 20 pulse/see rate, and pulse width of 50\% (Prasad et al., 2015).

Grey relational analysis was used with Taguchi technique in order to optimise the laser welding process for weld bead of AISI 904L material and on the basis of it was concluded that calculation of grey relational grade (GRG) assisted to quantify the integrated performance of weld bead in laser welding process (Sathiya and Jaleel, 2010). Many researchers applied grey relational method to optimize the process parameters in the drilling process of $\mathrm{Al} / \mathrm{SiC}$ metal matrix composite and it was concluded that the process was greatly improved (Haq et al., 2008). Dongxia et al. (2012) used Taguchi technique to optimize the laser welding 
parameters and they reported in their result that the effect of welding parameters on weld quality decreased in order of welding speed, wire feed speed followed by laser power. Ravikumar and Vijian (2014) coupled Taguchi method with GRA to solve multiresponse optimization problem and the authors was informed that the best welding process parameters are 140A, welding speed of $4 \mathrm{~mm} / \mathrm{sec}$, and wind velocity at $7 \mathrm{~m} / \mathrm{sec}$.

Lin (2012) integrated Taguchi technique with GRA (grey relational analysis) and ANN to minimize the gas metal arc welding process parameters and the authors mentioned in their result that the attribute, quality of gas metal arc welding process, is enhanced together by applying the planned approach. Xiong et al. (2014) used an ANN (artificial neural network) technique and a regression analysis of second order to predict the weld bead geometry by robotic GMA welding process and they informed that ANN performed better than regression analysis of the second order. Kshirsagar et al. (2020) tried to optimize the TIG welding parameters by applying a hybrid Nelder Mead-evolutionary algorithms technique and it was revealed from their result that this hybrid technique were better than that obtained from individual algorithms and also indicate significant reduction in the computation efforts. Yadav and Paswan (2019) predicted and optimized the weld bead geometry during the GMA welding process and they concluded that welding parameters such polarity, welding speed, welding current, and arc voltage influence weld bead geometry.

\section{Experimental procedure}

In this experimental work IS 2062 Structural steel is used as a base metal with the dimension of $75 \mathrm{~mm} X 55 \mathrm{~mm} X 10 \mathrm{~mm}$. The filler wire used to weld was ER 30S6. The chemical composition of the parent metal and filler wire is listed in Table 1, while the welding process parameters and their levels used in this study is listed in Table 2 respectively.

Table.1.Chemical composition (Wt\%) of base metal and filler wire

\begin{tabular}{|c|c|c|c|c|c|c|}
\hline Material & \% of C & \% of Si & \% of Mn & \% of P & \% of S & Fe \\
\hline IS 2062 & 0.079 & 0.45 & 1.65 & 0.012 & 0.03 & balance \\
\hline ER 70S6 & 0.19 & 0.98 & 1.62 & 0.025 & 0.028 & balance \\
Filler wire & & & & & & \\
\hline
\end{tabular}

Table.2. Welding process variable and their level

\begin{tabular}{|c|l|c|c|c|c|}
\hline Factor & \multicolumn{1}{|c|}{ Parameters } & Level-I & Level-II & Level-III & Level-IV \\
\hline A & Arc Voltage (V) & 24 & 26 & 28 & 30 \\
\hline B & Gas flow rate $(1 / \mathrm{min})$ & 10 & 15 & 20 & 25 \\
\hline C & Wire feed speed $(\mathrm{m} / \mathrm{min})$ & 300 & 350 & 400 & 450 \\
\hline
\end{tabular}

Figure 1 shows the schematic diagram of gas metal arc (GMA) welding process, which consists a nozzle thought to which the copper coated mild steel wire is fed and a inert gas i.e. $75 \% \mathrm{Ar}+25 \% \mathrm{CO}_{2}$ is passed as shielding gas through the nozzle to avoid any atmospheric contamination of weld pool from the atmosphere. Figure 2 shows the detailed cross section of a weld bead while Figure 3 shows the macrograph of weld bead.

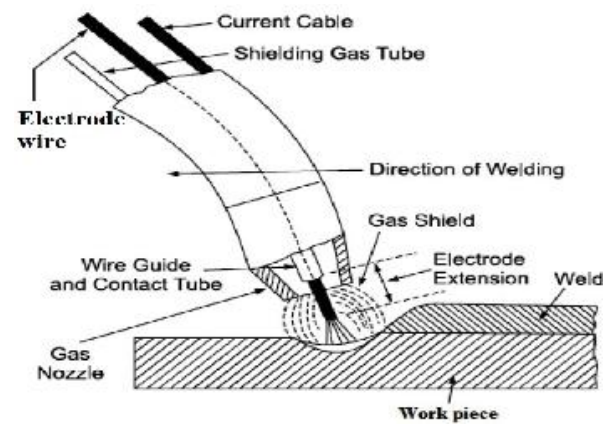

Figure 1. Schematic diagram of the GMA welding process 


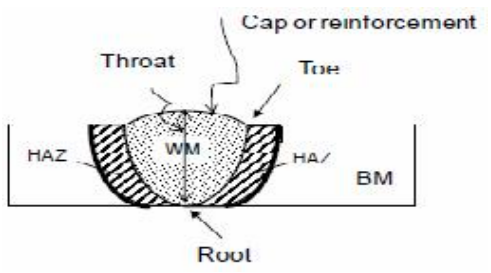

Figure 2. Detailed cross-section of a weld

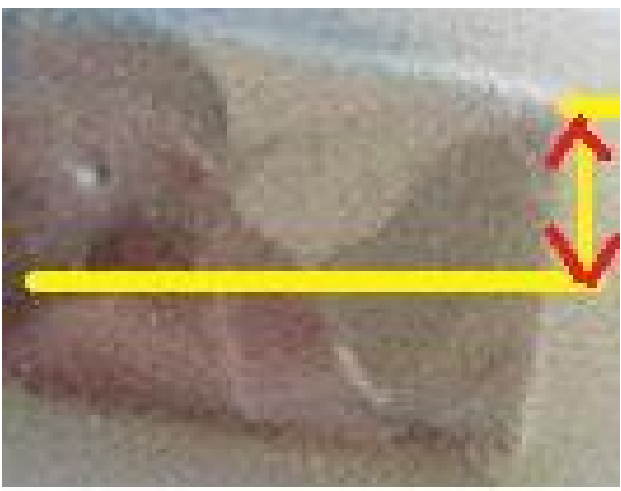

Figure 3. Macrograph of weld bead

Figure 4 shows the different weld beads produced in this experimental work.

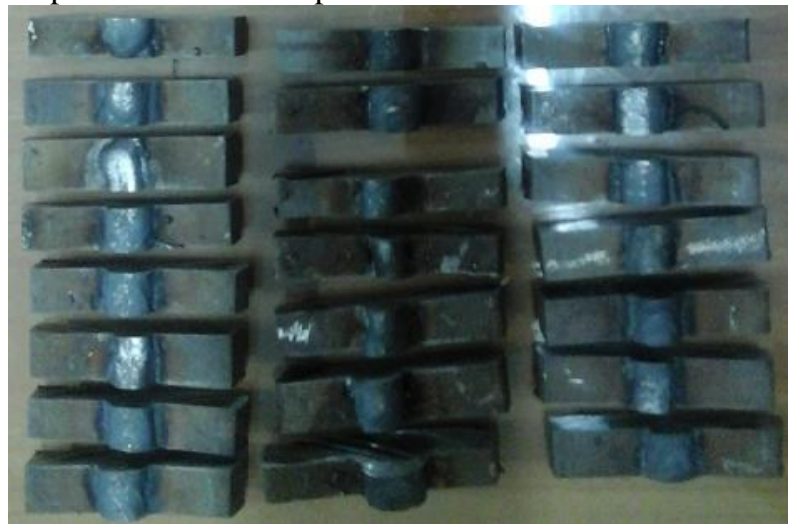

Figure 4. Actual photograph of experimental setup

In this study, weld bead, reinforcement, and penetration were measured at each run as responce parameters.experiments were planned as per Taguchi's (Patil and Naik, 2015) $\mathrm{L}_{16}$ orthogonal array technique (Table 3). Three parameters such as arc voltage, gas flow rate,and wire feed speed selected at four levels were sellected as process parameters.

Table 3. $\mathrm{L}_{16}$ orthogonal array and experimental results corresponding to the input parameters.

\begin{tabular}{|c|c|c|c|c|c|c|}
\hline $\begin{array}{c}\text { Trial } \\
\text { No. }\end{array}$ & $\begin{array}{c}\text { Arc } \\
\text { volatge } \\
(\mathbf{V})\end{array}$ & $\begin{array}{c}\text { Gas flow } \\
\text { rate } \\
(\mathbf{l} / \mathbf{h})\end{array}$ & $\begin{array}{c}\text { Wire feed } \\
\text { speed } \\
\text { (IPM) }\end{array}$ & $\begin{array}{c}\text { Weld bead } \\
\text { width } \\
(\mathbf{m m})\end{array}$ & $\begin{array}{c}\text { Reinforcement } \\
(\mathbf{m m})\end{array}$ & $\begin{array}{c}\text { Pentration } \\
(\mathbf{m m})\end{array}$ \\
\hline 1 & 24 & 10 & 300 & 13.15 & 3.85 & 9.10 \\
\hline 2 & 24 & 15 & 350 & 14.29 & 3.15 & 9.61 \\
\hline 3 & 24 & 20 & 400 & 14.39 & 2.87 & 9.28 \\
\hline 4 & 24 & 25 & 450 & 15.13 & 4.51 & 9.95 \\
\hline 5 & 26 & 10 & 350 & 16.11 & 4.35 & 9.30 \\
\hline 6 & 26 & 15 & 300 & 13.29 & 2.87 & 9.23 \\
\hline 7 & 26 & 20 & 450 & 14.95 & 2.41 & 9.38 \\
\hline 8 & 26 & 25 & 400 & 17.08 & 2.71 & 9.92 \\
\hline
\end{tabular}


Table 3 (cont'd). listed the $\mathrm{L}_{16}$ orthogonal array and experimental results corresponding to the input parameters.

\begin{tabular}{|c|c|c|c|c|c|c|}
\hline $\begin{array}{c}\text { Trial } \\
\text { No. }\end{array}$ & $\begin{array}{c}\text { Arc } \\
\text { volatge } \\
(\mathbf{V})\end{array}$ & $\begin{array}{c}\text { Gas flow } \\
\text { rate } \\
(\mathbf{l} / \mathbf{h})\end{array}$ & $\begin{array}{c}\text { Wire feed } \\
\text { speed } \\
\text { (IPM) }\end{array}$ & $\begin{array}{c}\text { Weld bead } \\
\text { width } \\
(\mathbf{m m})\end{array}$ & $\begin{array}{c}\text { Reinforcement } \\
(\mathbf{m m})\end{array}$ & $\begin{array}{c}\text { Pentration } \\
(\mathbf{m m})\end{array}$ \\
\hline 9 & 28 & 10 & 400 & 18.19 & 3.43 & 10.08 \\
\hline 10 & 28 & 15 & 450 & 13.89 & 1.39 & 10.00 \\
\hline 11 & 28 & 20 & 300 & 14.83 & 1.81 & 9.00 \\
\hline 12 & 28 & 25 & 350 & 17.06 & 2.97 & 9.98 \\
\hline 13 & 30 & 10 & 450 & 18.25 & 3.78 & 9.24 \\
\hline 14 & 30 & 15 & 400 & 15.35 & 4.26 & 8.54 \\
\hline 15 & 30 & 20 & 350 & 13.21 & 2.81 & 8.89 \\
\hline 16 & 30 & 25 & 300 & 12.54 & 1.95 & 8.75 \\
\hline
\end{tabular}

\section{Results and Discussions}

\subsection{Grey relation analysis}

The grey relation analysis was proposed by Deng (1982). The grey means the ancient data with poor, incomplete and uncertain information in the grey relation theory. The steps followed in the optimization process are:

Step 1: Calculation of grey relational generation

Let us assume that the sequence of original reference and sequence for comparison be denoted as $x o(k)$ and $x i(k), i=1,2, \ldots, m$; $\mathrm{k}=1,2, \ldots, \mathrm{n}$, correspondingly, where $\mathrm{m}$ is the experimental numbers to be considered, and $\mathrm{n}$ is the total number of observation data. Optimization of multiple responses can be simultaneously performed with Grey Relation Analysis (GRA) to determine the best levels that consists of many outputs (Deng, 1989) with the meager information available; grey relation analysis can evaluate or judge the performances of intricate process which consist more than one output. In grey relation analysis, the raw data have to be pre-processed into a quantitative index for further investigation.

In grey-relation generation, the normalized bead width, reinforcement, and penetration, corresponding the lower-the-better condition is shown as

$$
x_{i}(k)=\frac{\max x_{i}(k)-x_{i}(k)}{\max x_{i}(k)-\min x_{i}(k)}
$$

Bead penetration should follow for Higher-the-better order which can be shown as

$$
x_{i}(k)=\frac{x_{i}(k)-\min x_{i}(k)}{\max x_{i}(k)-\min x_{i}(k)}
$$

Where $\mathrm{Xi}(\mathrm{k})$ denotes the data sequence after pre-processing, $\mathrm{xi}(\mathrm{k})$ denotes the original sequence, highest value of $\mathrm{xi}(\mathrm{k})$ is max $\mathrm{xi}$ $(\mathrm{k})$, lowest value of $\mathrm{xi}(\mathrm{k})$ is min $\mathrm{xi}(\mathrm{k})$ imply normalizing the data for lower-the-better condition is shown as

A Grey relational coefficient (GRC) can be determined, as expressed in Eq. (3):

$$
\xi_{i}(k)=\frac{\Delta \min +p \Delta \max }{\Delta x_{i}(k)+p \Delta \max }
$$

$\Delta \mathrm{x}_{\mathrm{i}}(\mathrm{k})$ denotes the deviation sequence, which is calculated by

Where $\Delta \mathrm{x}_{\mathrm{i}}(\mathrm{k})=\left\|\mathrm{X}_{\mathrm{o}}^{*}(\mathrm{k})-\mathrm{X}_{\mathrm{i}}^{*}(\mathrm{k})\right\|, \Delta \max .(\mathrm{k})=\frac{\max .}{\forall j i \zeta} \frac{\max }{\forall k} \quad\left\|\mathrm{Xo}^{*}(\mathrm{k})-\mathrm{Xi}^{*}(\mathrm{k})\right\|$,

$\Delta \min .(\mathrm{k})=\frac{\max }{\forall j i \zeta} \frac{\max }{\forall k}\left\|\mathrm{Xo}^{*}(\mathrm{k})-\mathrm{Xi}^{*}(\mathrm{k})\right\|$, where $\zeta$ is the distinguishing coefficient and in current study $\mathrm{p}=0.5$ is used.

The second standardized formula is suitable for defect - type factor.

$$
x_{i}(k)=\frac{\left|x_{i}(k)-x_{0}(k)\right|}{\max x_{i}(k)-x_{0}(k)}
$$

The third standardized formula is suitable for the medium- type factor.

The grey relation (GR) degree can be estimated by steps as given by:

The absolute difference of the compared series and the referential series should be obtained by using the following formula: 


$$
\Delta x_{i}(k)=\left|x_{0}(k)-x_{i}(k)\right|
$$

Step 2: Estimation of grey relational coefficient $(G R C)$

After pre-processing, a grey relation coefficient (GRC) can be calculated with the pre-processedsequence.it express the relationship between ideal normalize value and actual normalized values results.

Step 3: Estimation of grey relational grade $(G R G)$

The weighted sum of grey relational coefficient is known as grey relational grade (GRC), and is referred as follows and determine by Equation (6). It shows the relation between the normalization value and ideal normalization values of the performance characteristics.

$$
\gamma_{i}=\frac{1}{n} \sum_{k=1}^{n} \zeta(k)
$$

where $\mathrm{n}=$ number of process responses. The higher value of grey relational grade corresponds to the intense relational degree between the interface sequence $\mathrm{x}_{\mathrm{o}}(\mathrm{k})$ and the comparability sequences $\mathrm{x}_{\mathrm{i}}(\mathrm{k})$.

Table 4. Data processing of each performance characteristics (Normalized values)

\begin{tabular}{|c|c|c|c|}
\hline $\begin{array}{c}\text { Experiment } \\
\text { No }\end{array}$ & WB & Reinforcement & Penetration \\
\hline 1 & 0.893 & 0.212 & 0.364 \\
\hline 2 & 0.694 & 0.436 & 0.695 \\
\hline 3 & 0.676 & 0.526 & 0.481 \\
\hline 4 & 0.546 & 0.000 & 0.916 \\
\hline 5 & 0.375 & 0.051 & 0.494 \\
\hline 6 & 0.869 & 0.526 & 0.448 \\
\hline 7 & 0.578 & 0.673 & 0.545 \\
\hline 8 & 0.205 & 0.577 & 0.896 \\
\hline 9 & 0.011 & 0.346 & 1.000 \\
\hline 10 & 0.764 & 1.000 & 0.948 \\
\hline 11 & 0.599 & 0.865 & 0.299 \\
\hline 12 & 0.208 & 0.494 & 0.935 \\
\hline 13 & 0.000 & 0.234 & 0.455 \\
\hline 14 & 0.508 & 0.080 & 0.000 \\
\hline 15 & 0.883 & 0.545 & 0.227 \\
\hline 16 & 1.000 & 0.821 & 0.136 \\
\hline
\end{tabular}

To determine the optimum process parameters and their effect on selected output parameters such as weld the weld bead, reinforcement, and penetration have been measured. Data related to weld bead (WB), reinforcement, and penetration have been furnished in Table 4.

Table 5. Data processing of each performance characteristics (grey relation analysis) and grey relation grade

\begin{tabular}{|c|c|c|c|c|c|}
\hline $\begin{array}{c}\text { Experiment } \\
\text { No. }\end{array}$ & WB & Reinforcement & Penetration & GRG & Rank \\
\hline 1 & 0.824 & 0.388 & 0.440 & 0.551 & 12 \\
\hline 2 & 0.620 & 0.470 & 0.621 & 0.570 & 10 \\
\hline 3 & 0.607 & 0.513 & 0.490 & 0.537 & 13 \\
\hline 4 & 0.524 & 0.333 & 0.856 & 0.571 & 9 \\
\hline 5 & 0.444 & 0.345 & 0.497 & 0.429 & 14 \\
\hline 6 & 0.792 & 0.513 & 0.475 & 0.593 & 3 \\
\hline 7 & 0.542 & 0.605 & 0.524 & 0.557 & 11 \\
\hline 8 & 0.386 & 0.542 & 0.828 & 0.585 & 7 \\
\hline 9 & 0.336 & 0.433 & 1.000 & 0.590 & 4 \\
\hline 10 & 0.679 & 1.000 & 0.906 & 0.862 & 1 \\
\hline
\end{tabular}


Table 5 (cont'd). Data processing of each performance characteristics (grey relation analysis) and grey relation grade

\begin{tabular}{|c|c|c|c|c|c|}
\hline $\begin{array}{c}\text { Experiment } \\
\text { No. }\end{array}$ & WB & Reinforcement & Penetration & GRG & Rank \\
\hline 11 & 0.555 & 0.788 & 0.416 & 0.586 & 6 \\
\hline 12 & 0.387 & 0.497 & 0.885 & 0.590 & 5 \\
\hline 13 & 0.333 & 0.395 & 0.478 & 0.402 & 15 \\
\hline 14 & 0.504 & 0.352 & 0.333 & 0.396 & 16 \\
\hline 15 & 0.810 & 0.523 & 0.393 & 0.575 & 8 \\
\hline 16 & 1.000 & 0.736 & 0.367 & 0.701 & 2 \\
\hline
\end{tabular}

Figure 5 shows the S/N ratio (signal to noise) for overall Grey relational grade calculated using HB (Higher-the-better) criterion is calculated as:

$$
\mathrm{S} / \mathrm{N}(\text { Higher the better })=-10 \log \left[\frac{1}{n} \sum_{i=1}^{n} \frac{1}{y^{2}}\right]
$$

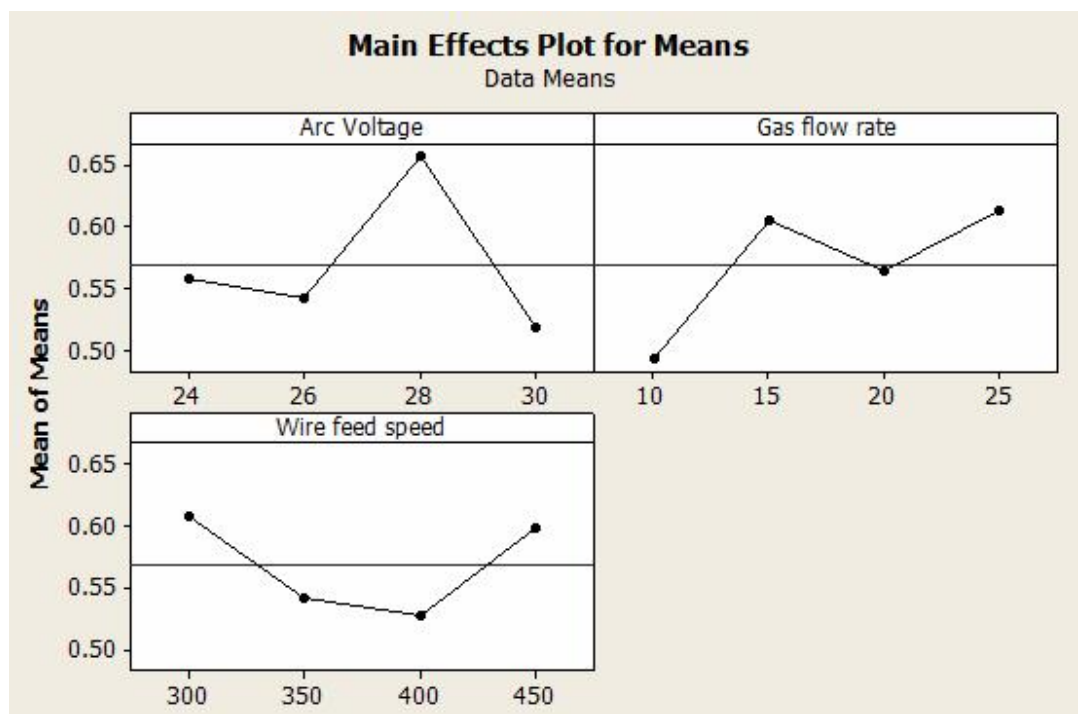

Figure 5. Main effect plot for grey relation grade

The higher values of mean grey relational grade (GRG) as shown in Figure 5, gives the minimum value of weld bead,reinforcement,and maximum value of penetration. From Figure 5 it is very clear that optimal settings for multi-responses becomes V3-G4-W1 i.e. arc voltage is $28 \mathrm{~V}$, gas flow rate $25 \mathrm{l} / \mathrm{m}$, and wire feed speed is $300 \mathrm{IPM}$.

\subsection{Analysis of Variance (ANOVA)}

ANOVA is a statistical tool, which is used to reveal the level of significance of influence of factors. Result of ANOVA for overall grey relation grade (GRG) has been listed in Table 6. From Table 6, it is very clear that arc voltage having the most significant effect on weld bead (Reddy et al., 2020) followed by gas flow rate and wire feed speed respectively and it is validated by previous research work (Kant et al., 2020).

Table 6. Analysis of Variance

\begin{tabular}{|c|c|c|c|c|c|c|c|}
\hline Source & DF & Seq SS & Adj SS & Adj MS & F & P & $\begin{array}{c}\text { \% } \\
\text { Contribution }\end{array}$ \\
\hline Arc Voltage & 3 & 0.04486 & 0.04486 & 0.01495 & 1.07 & 0.430 & 24.35 \\
\hline Gas flow rate & 3 & 0.03578 & 0.03578 & 0.01193 & 0.85 & 0.515 & 19.42 \\
\hline Wire feed speed & 3 & 0.01956 & 0.01956 & 0.00652 & 0.47 & 0.717 & 10.62 \\
\hline Error & 6 & 0.08403 & 0.08403 & 0.01400 & & & 45.61 \\
\hline Total & 15 & 0.18422 & & & & & 100 \\
\hline
\end{tabular}


Figure 6 shows grey relation grade values from Table 5, for all 16 experiments run as per $\mathrm{L}_{16}$ orthogonal arrays and it was observed from Figure 6 that change in the response when factors go from one level to other. Figure 4 also reveals that trial No. 10 has the highest grey relation grade value.

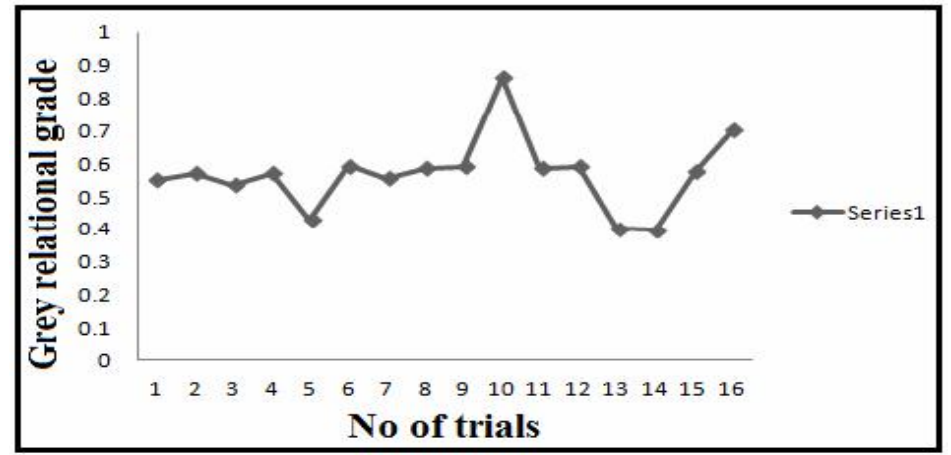

Figure 6. Grey relation grade for multi response

\section{Conclusion}

In this research article, the Taguchi technique was integrated with GRA (Grey relational analysis) and used to determine the best optimal GMA welding process parameters to get the acceptable depth of penetration (DOP) and lowest weld bead height, and weld bead width.

The following main outcomes of this study can be highlighted by the following:

1. Weld bead width, reinforcement, were measured to identify the optimal welding parameter combination.

2. The multiple responses performance characteristic was converted to an optimization of a single performance characteristic from the stance of the correlations between arc voltage, gas flow rate, and wire feed speed to obtain enhanced outcomes for weld bead, reinforcement, and penetration.

3. From result it was observed that the optimal welding process parameters were arc voltage $28 \mathrm{~V}$, gas flow rate $25 \mathrm{l} / \mathrm{m}$, and wire feed speed 300 IPM. Further it has been noticed that ANOVA shows that arc voltage having the most important effect followed by gas flow rate and wire feed speed respectively.

4. The optimum result assists the manpower to getting the preferred performance measure which curtail the manpower's time, expenditure and assist in enhancing the yield.

\section{References}

Datta S, Bandyopadhyay A, Pal P.K, 2008, Grey-based Taguchi method for optimization of bead geometry in submerged arc beadon-plate welding, International Journal of Advanced Manufacturing Technology, Vol. 39, pp. 1136-1143

Deng, J., 1982, Control problem of grey system, System and Control Letter, Vol.1, pp. 288-284.

Deng J., 1989 Introduction to Grey System Theory. The Journal of Grey System, Vol. 1, No. 1, pp. 1-24.

Dongxia Y., Lixiaoyan,Hedingyong,Niezuoren,Huanghui,2012, Optimization of weld bead geometry in laser welding with filler wire process using Taguchi's approach, Optics \& Laser Technology 44,2020-2025.

Esme U., Bayramoglu M, Kazancoglu Y, Ozgun S,2009, Optimization of weld bead geometry in TIG welding process using grey relation analysis and Taguchi method, Materials and Technology, Vol. 43, No. 3, pp. 143-149.

Haq A.N, Marimuthu P., Jeyapaul R.,2008, Multi response optimization of machining parameters of drilling Al/SiC metal matrix composite using grey relational analysis in the Taguchi method, The International Journal of Advanced Manufacturing Technology, Vol. 37, No. 3-4, pp. 250-255.

Kshirsagar R., Jones S., Lawrence J., Tabor J.,2020, Optimization of TIG welding parameters using a hybrid Nelder Meadevolutionary algorithms method, Journal of Manufacturing and Materials Processing, Vol.4, No.10, 1-22, DOI: 10.3390/jmmp4010010

Kant R., Pandey S.,Singh R., Tanwar P., 2020, Influence of process parameters onweld bead geometry and mechanical properties in GTAW, Trends in Manufacturing Processes, Part of the Lecture Notes on Multidisciplinary Industrial Engineering Book Series (LNMUINEN), pp 111-117, DOI: 10.1007/978-981-32-9099-0_12

Lin H.L., 2012, The use of the Taguchi method with grey relational analysis and a neural network to optimize a novel GMA welding process, Journal of Intelligent Manufacturing, Vol.23, pp. 1671-1680

Prasad K. S., Rao Ch. S., Rao D. N,2013, Application of grey relational analysis for optimizing weld bead geometry parameters of pulsed current micro plasma arc welded AISI 304L stainless steel sheets, International Journal of Advanced Design and Manufacturing Technology, Vol. 6, No. 1, pp. 79-86 
Prasad K.S, Chalamalasetti S.R, Damera N.R,,2015, Application of grey relational analysis for optimizing weld bead geometry parameters of pulsed current micro plasma arc welded inconel 625 sheets, International Journal of Advanced Manufacturing Technology, Vol.78, No. 1-4, pp. 625-632.

Patil U. V., Naik G. R.,2015, Process parameter optimization of bead geometry for AISI 446 in GMAW process using grey-based Taguchi method, IOSR Journal of Mechanical and Civil Engineering, Vol.12, No. 6, Ver. II, pp. 21-29.

Reddy P.V.R R., Reddy G.C.M., Rao B.V.S., Laxmaiah G., 2020, Effect of various parameters on the bead geometry and flexural strength of MIG welded joint, International Journal of Innovative Technology and Exploring Engineering, Vol.9, No. 3, pp. 555-559, DOI: 10.35940/ijitee.C8098.019320

Rizvi S.A, Ali W., 2009, Advanced Welding Technology, Kataria \& Sons (P) Ltd., New Delhi, p. 50

Ravikumar S.M., Vijian P., 2014, Optimization of weld bead geometry in shielded metal arc welding using Taguchi based grey relational analysis, International Journal of Mechanical \& Mechatronics Engineering, Vol.14, No.4, 86-91

Sharma S.K, Rizvi S.A, Kori R. P,2014, Optimization of process parameters in turning of AISI 8620 steel using Taguchi and grey Taguchi analysis, International Journal of Engineering Research and Applications, Vol. 4, No. 3, pp. 51-57

Sathiya P., Jaleel M.Y A, 2010, Grey-based Taguchi method for optimization of bead geometry in laser bead-on-plate welding, Advances in Production Engineering \& Management, Vol.5, No.4, 225-234

Xiong, J., Zhang, G., Hu, J., Wu, L., 2014, Bead geometry prediction for robotic GMAW-based rapid manufacturing through a neural network and a second-order regression analysis. Journal of Intelligent Manufacturing, Vol. 25, pp. 157-163, doi:10.1007/s10845-011-0526-4.

Yadav J., Paswan M.,2019, Prediction and optimization of weld bead geometry, International Journal of Innovative Technology and Exploring Engineering, Vol. 8, No. 10, pp. 2735-2742. DOI: 10.35940/ijitee.J9564.0881019

\section{Biographical notes}

Dr.Saadat Ali Rizvi received M.E (Production Engineering) from DTU, New Delhi and Ph.D. from Indian Institute of Technology (BHU) Varanasi, India in 2005 and 2018, respectively. He is a faculty member in University Polytechnic in Faculty of Engineering \& technology, Jamia Millia Islamia,New Delhi.His research interests include machinability,Welding,Casting,optimization \& control, Fuzzy etc. He is a Member of IE (India), life time member of ISTE, IIW, and Kolkatta. He has written few books related to Mechanical Engineering students.

Mr. Wajahat Ali is a working in the Department of Mechanical Engineering, SCRIET (CCS University, Meerut). He has written few books related to Mechanical Engineering students. His research interests include machinability, welding, casting, optimization \& control, fuzzy etc.

Received December 2020

Accepted April 2020

Final acceptance in revised form April 2020 